\title{
Lack of evidence for monosomy 1 p36 in patients with Prader-Willi-like phenotype
}

\author{
V.R. Rodríguez, L.F. Mazzucato and J.M. Pina-Neto \\ Departamento de Genética, Faculdade de Medicina de Ribeirão Preto, Universidade de São Paulo, \\ Ribeirão Preto, SP, Brasil \\ Correspondence to: J.M. Pina-Neto, Departamento de Genética, FMRP-USP, Av. Bandeirantes, 3900, \\ 14049-900 Ribeirão Preto, SP, Brasil \\ Fax: +55-16-3633-0069. E-mail: jmdpneto@fmrp.usp.br
}

\begin{abstract}
Monosomy 1 p36 is the most common subtelomeric microdeletion syndrome with an incidence rate estimated to be 1 in 5000 births. A hypothesis of a similarity between patients with $1 \mathrm{p} 36$ deletion and those with Prader-Willi syndrome and the existence of two different phenotypes for $1 \mathrm{p} 36$ microdeletion has been suggested. The main objective of the present study was to determine the existence of 1 p36 microdeletion in a sample of patients with mental retardation, obesity and hyperphagia who tested negative by the methylation test for Prader-Willi syndrome. Sixteen patients (7 females, 9 males), 16-26 years old, were evaluated with high-resolution cytogenetic analysis at 550-850 band levels and with 11 polymorphic microsatellite markers located in the 1 p36 region. All patients had normal cytogenetic and molecular results. The results obtained by high-resolution cytogenetic methodology were confirmed by the molecular analyses. We did not detect a 1 p36 microdeletion in 16 subjects with the Prader-Willi-like phenotype, which reinforces that no correlation seems to exist between Prader-Willi-like phenotype and the 1 p36 microdeletion syndrome.
\end{abstract}

Key words: Monosomy 1p36; 1 p36 microdeletion syndrome; Prader-Willi syndrome; Prader-Willi-like phenotype

Publication supported by FAPESP.

Received May 7, 2007. Accepted July 15, 2008

We tested for the $1 \mathrm{p} 36$ microdeletion in 16 patients (1626 years old) with the Prader-Willi-like phenotype who tested negative for the Prader-Willi syndrome using the methylation test by Southern blot with the Kb17 probe (1).

Clinical characterization of the patients (Table 1) was performed using a protocol with the characteristics of Prader-Willi phenotype and 1p36 microdeletion syndrome based on the literature (2-11). The protocol was approved by the institutional Ethical Review Board and written informed consent was obtained from the parents of all patients. Twelve patients were examined by the authors, and the other 4 were studied by the University Hospital of Rio Grande do Sul (Porto Alegre, RS, Brazil).

Two methods were used to identify the 1p36 microdeletion. First, the high-resolution 1p36 cytogenetic region studies. For this, we obtained metaphases from phytohemagglutinin-stimulated peripheral blood lymphocytes using the methotrexate and thymidine synchronization method (12) with GTG banding for cytogenetic analysis per- formed at 550-850 band levels. We analyzed 40 metaphases for each patient. The levels reached to exclude mosaics were $\leq 6 \%$ for a confidence interval of $99 \%$, and $\leq 8$ and $\leq 11 \%$ for 95 and $90 \%$ confidence intervals, respectively (13). Secondly, polymorphic markers of the 1p36 region were analyzed using 11 dinucleotide or tetranucleotide polymorphisms (D1S243, D1S468, D1S2660, D1S2795, D1S2870, D1S2145, D1S214, D1S2663, D1S450, D1S244, D1S2667). For this assessment, we collected blood samples from patients and their parents and extracted genomic DNA by a standard method, and later performed amplification in a volume of $15 \mu \mathrm{L}$ with 50 ng genomic DNA, 6 pmol of each primer, and 0.5 unit of thermostable DNA polymerase in a buffer containing 10 $\mathrm{mmol} / \mathrm{L}$ Tris- $\mathrm{HCl}, \mathrm{pH} 8.3,50 \mathrm{mmol} / \mathrm{L} \mathrm{KCl}, 1.5 \mathrm{mmol} / \mathrm{L}$ $\mathrm{MgCl}_{2}$, and $100 \mu \mathrm{mol} / \mathrm{L}$ of each dNTP, and $0.2 \mu \mathrm{L} 32-\mathrm{P}$ dNTP was added per reaction. Thirty-one amplification cycles were used with $35 \mathrm{~s}$ at $95^{\circ} \mathrm{C}, 35 \mathrm{~s}$ at $55-62^{\circ} \mathrm{C}$ for primer annealing, and $35 \mathrm{~s}$ at $72^{\circ} \mathrm{C}$ for extension. Products 
were separated on $6 \%$ polyacrylamide/urea gels and analyzed based on mapping data obtained from <http://www. Ensembl.org/Homo_sapiens $>$ for chromosome 1. In order to establish which polymorphic loci were deleted, alleles were compared between the patient and their parents.
After the high-resolution cytogenetic analysis, no subtelomeric deletion in the $1 \mathrm{p} 36$ region was observed in 40 metaphases for each patient. All 11 dinucleotide and tetranucleotide repeat polymorphic markers for each family were negative for 1 p36 microdeletions. In cases of homozygosity in one marker, the heterozygosity of other markers was used to indicate lack of deletion (Figure 1).

Our patient sample (Table 1) was consistent with the Prader-Willi-like phenotype because $100 \%$ had mental retardation associated with obesity and hyperphagia, and a high prevalence of other important signs of PraderWilli syndrome, i.e., developmental delay (81\%), hypotonia $(94 \%)$, infant feeding problems (94\%), abusive behavior (75\%), and other associated dysmorphic features.

The number and position of the polymorphic markers in the 1 p36 region used are located in all six intervals of the microdeletion distribution, as suggested by Wu et al. (14) and observed by Heilstedt et al. (11). Furthermore, we used two polymorphic markers (D1S243 and D1S468) mapped inside the obesity/hyperphagia chromosomal segment $1 \mathrm{p} 36.33-36.32$ suggested by D'Angelo et al. (15). All results obtained in the polymorphic marker analyses in our patient sample were normal. On the other hand, all 40 metaphases analyzed by the highresolution technique were also normal, revealing a correspondence between cytogenetic and molecular analysis and reinforcing the observation of Heilstedt et al. (16) that $98 \%$ of this microdeletion could be detected by high-resolution chromosome analysis.

Slavotinek et al. (8) reviewed 39 cases reported to have pure $1 \mathrm{p} 36$ deletion and only 2 cases $(5.1 \%)$ had the Prader-Willi-like phenotype. Shapira et al. (7) described 13 cases of the pure 1 p36 deletion and 2 cases (15\%) had obesity. D'Angelo et al. (15) have described 1 case of pure $1 \mathrm{p} 36$ deletion within a group of 41 cases with Prader-Willi-like phenotype. The phenotype defined as monosomy $1 \mathrm{p} 36$ by Heilstedt et al. (11) excluded hyperphagia/obesity and the relationship between this microdeletion syndrome and the Prader-Willi-like phenotype. Our results do not confirm the suggestion of D'Angelo et al. (15) about a specific hyperphagia/obesity chromosomal region in 1 p36 but reinforce the opinion of Heilstedt et al. (11). 
Shaffer and Heilstedt (17) affirm that the phenotype of 1 p36 monosomy is very characteristic with high similarities among the patients. If we consider that obesity is a very common clinical sign associated with mental retardation,

1. Kubota T, Sutcliffe JS, Aradhya S, Gillessen-Kaesbach G, Christian SL, Horsthemke B, et al. Validation studies of SNRPN methylation as a diagnostic test for Prader-Willi syndrome. Am J Med Genet 1996; 66: 77-80.

2. Eugster EA, Berry SA, Hirsch B. Mosaicism for deletion 1 p36.33 in a patient with obesity and hyperphagia. Am J Med Genet 1997; 70: 409-412.

3. Finelli P, Giardino D, Russo S, Gottardi G, Cogliati F, Grugni $\mathrm{G}$, et al. Refined FISH characterization of a de novo 1p22p36.2 paracentric inversion and associated 1p21-22 deletion in a patient with signs of $1 \mathrm{p} 36$ microdeletion syndrome. Am J Med Genet 2001; 99: 308-313.

4. Keppler-Noreuil KM, Carroll AJ, Finley WH, Rutledge SL. Chromosome $1 p$ terminal deletion: report of new findings and confirmation of two characteristic phenotypes. J Med Genet 1995; 32: 619-622.

5. Reish O, Berry SA, Hirsch B. Partial monosomy of chromosome 1p36.3: characterization of the critical region and delineation of a syndrome. Am J Med Genet 1995; 59: 467475.

6. Sandlin CJ, Dood BS, Dumars KW. Phenotypes associated with terminal deletion of the short arm of chromosome 1. Am J Hum Genet 1995; 57A: 125.

7. Shapira SK, McCaskill C, Northrup H, Spikes AS, Elder FF, Sutton VR, et al. Chromosome 1p36 deletions: the clinical phenotype and molecular characterization of a common newly delineated syndrome. Am J Hum Genet 1997; 61: 642-650.

8. Slavotinek A, Shaffer LG, Shapira SK. Monosomy 1p36. J Med Genet 1999; 36: 657-663.

9. Wargowski D, Sekhon G, Laxova R, Thompson K, Kent C. and that it is now a public health problem, we question if these patients, who were described as being obese, are really representative of this microdeletion syndrome.
Terminal deletions of band 1p36: emergence of two overlapping phenotypes. Am J Hum Genet 1991; 49: 278.

10. Wenger SL, Steele MW, Becker DJ. Clinical consequences of deletion 1p35. J Med Genet 1988; 25: 263.

11. Heilstedt HA, Ballif BC, Howard LA, Lewis RA, Stal S, Kashork CD, et al. Physical map of 1p36, placement of breakpoints in monosomy $1 \mathrm{p} 36$, and clinical characterization of the syndrome. Am J Hum Genet 2003; 72: 12001212.

12. Yunis JJ. High resolution of human chromosomes. Science 1976; 191: 1268-1270.

13. Hook EB. Exclusion of chromosomal mosaicism: tables of $90 \%, 95 \%$ and $99 \%$ confidence limits and comments on use. Am J Hum Genet 1977; 29: 94-97.

14. Wu YQ, Heilstedt HA, Bedell JA, May KM, Starkey DE, McPherson JD, et al. Molecular refinement of the $1 \mathrm{p} 36$ deletion syndrome reveals size diversity and a preponderance of maternally derived deletions. Hum Mol Genet 1999; 8: 313-321.

15. D'Angelo CS, Da Paz JA, Kim CA, Bertola DR, Castro Cl, Varela MC, et al. Prader-Willi-like phenotype: investigation of 1 p36 deletion in 41 patients with delayed psychomotor development, hypotonia, obesity and/or hyperphagia, learning disabilities and behavioral problems. Eur J Med Genet 2006; 49: 451-460.

16. Heilstedt HA, Ballif BC, Howard LA, Kashork CD, Shaffer LG. Population data suggest that deletions of $1 \mathrm{p} 36$ are a relatively common chromosome abnormality. Clin Genet 2003; 64: 310-316.

17. Shaffer $\mathrm{H}$, Heilstedt $\mathrm{HA}$. Terminal deletion of $1 \mathrm{p} 36$. Lancet 2001; 9: 358. 